\section{The uses of social power in early childhood}

Dr Sandra Della Porta from
Brock University in Ontario,
Canada, investigates the use of
social power in early childhood.
Her most recent research
demonstrates how children's
use and effectiveness of power
strategies develops over time,
but can also be influenced by
birth order. The study involved
analysis of naturally occurring
family conflict, to ensure
complex family dynamics such
as parent-child and sibling
relationships were observed.

Erly childhood is a period of - rapid learning and development,

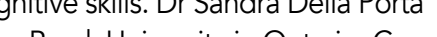
has Bock University in Ontario, Canada, focusing on the development and use of power strategies in early childhood In a social context, power is used to influence another person in the way they think or act, and we often implement power strategies during times of conflic. Studying family disagreements is an important means by which researchers can investigate children's use of power strategies. Della Porta believes that these learning moments help younger children to develop their own power strateg for use in future conflicts and the ment of social relationships.

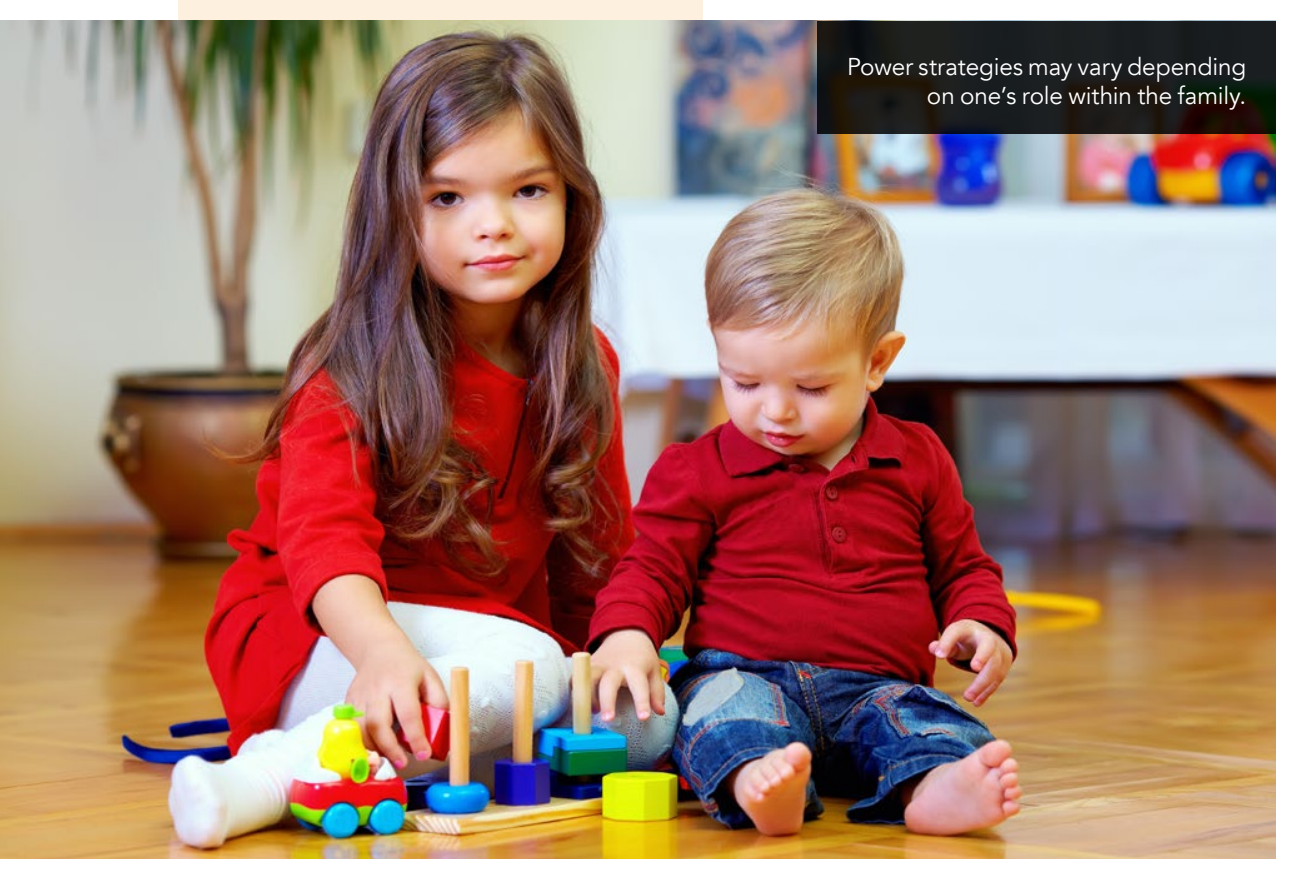

TYPES OF POWER STRATEGIES (Y) trategies to achieve a personal goal inferred in conflict based on a winning or losing outcome Previous research has highlighted that within early childhood there are five main power strategies. The first is 'coercion', which involves using threats or physical aggression, such as hitting, grabbing or pushing. The second is 'reward', which sees children using positive and negative reinforcement to influence an outcome, for example exchanging something they have to get a toy they want. The third is "egitimacy" which is related to internalised values, rights or authority. The fourth is labeled 'simple', and involves a child demanding something without any explanation.

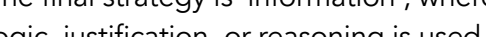
logic, justicication, or reasoning is used actions or thoughts. The person's types vary in the sophistication of their cognition. Coercive and simplistic power are considered to require more basic skills, whereas information requires more advanced cognition. A previous study conducted by Della Porta and her research colleague, revealed that different power strategies may be used depending on a person's role within the family, particularly within a mother-child relationship.

\section{POLYADIC FAMILY CONFLICTS} Many previous research studies focusing on strategies to resolve conflict in early childhood, have analysed interactions dyadically, between two family memb
This may not accurately reflect the

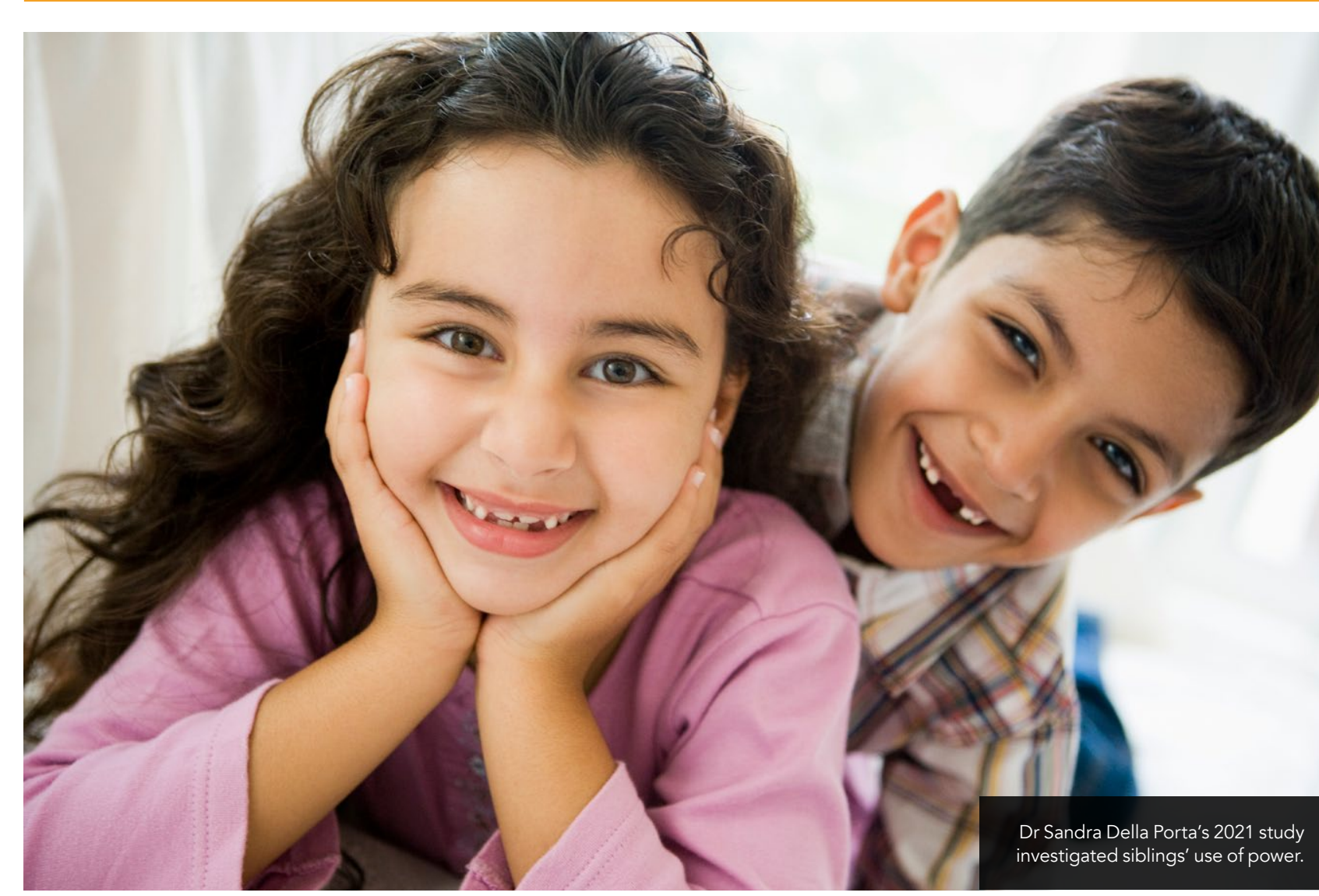
as this is an emotional unit. Therefore, complex social dynamics that take place within families, especially during conflicts. According to the 'Family Systems Theory', individuals are best understood within the contexts of family, Della Porta feels it is important to observe polyadic conflicts, involving three or more family mem

siblings used 'reward' power more effectively to elicit winning outcomes within family conflict.

Della Porta and her research team undertook a further study in 2019, which investigated power between parents and children in family conflict, and a more recent study in 2021, investigating sibling use of power and its development longitudinally. Interestingly, research

\section{EARLY CHILDHOOD USE OF POWER} the use of power strateges betwin older and younger siblings. They found no variance in the siblings' use of power, leading of power, leading
the researchers to speculate that the younger sibling may have developed their skills to match those of the older sibling. They did find a difference in the effectiveness of the power strategies
used by each sibling Older siblings used by each sibling. Older siblings used 'legitmate' power more successfully possibly due to their advanced development in terms of values

children, aged two to four years old, when ( their parents. These younger child be taken with parents, as they are able
Della Porta's research provides an important insight into how children's power strategies develop over time

than siblings. This research also found evidence of developmental changes over time, which evidences that socialcognitive learning does occur during

STUDY AIMS AND METHODOLOGY For Della Porta's 2021 study, forty Canadian families, with two parents and wo children, were observed two when their children were two was four years old the second was when the shad reached four and six years . This enabled the research team to compare the effects of birth order, by ing behaviour of the four-yearof being an older or younger sibling. In-home observations were conducted, and the families were instructed to act normally, undertaking their parents, but also deployed 'simple' activities. The observers remained and 'reward' based strategies when in relatively unobtrusive, recording the conflict with siblings. It was theorised that conversations between family members, a less cognitively complex approach may while simultaneously dictating what they 
and nonverbal behaviours. Conflict sequences were identified when on actions or statements. The use of pow strategies was then coded within ouch conversational turn throughout the conflict. Resolution of the family conflict was categorised as either win-los compromise, or no resolution.

Ahead of the results, Della Porta and her team made three predictions about the outcome of this study, influenced by previous research findings. They believed that children's use of power strategies would become more cognitively complex across the twoyear period. In addition, they forecast that four-year-olds who were the younger sibling would demonstrate more advanced uses of power, possibly their older siblings. Finally, they expected that birth order would impact effective use of power.

\section{RESULTS AND KEY LEARNINGS} The results from this study did demonstrate some support for an
increased sophistication of power use over time. In the first time period, both siblings were more likely to use 'coercive' power, involving threats and acts of aggression. This may be explained by the difficulty that pre-schoolers have in regulating their emotional reactions, especially when frustrated or facing conflict. In the second time 'information' power, which is cogn

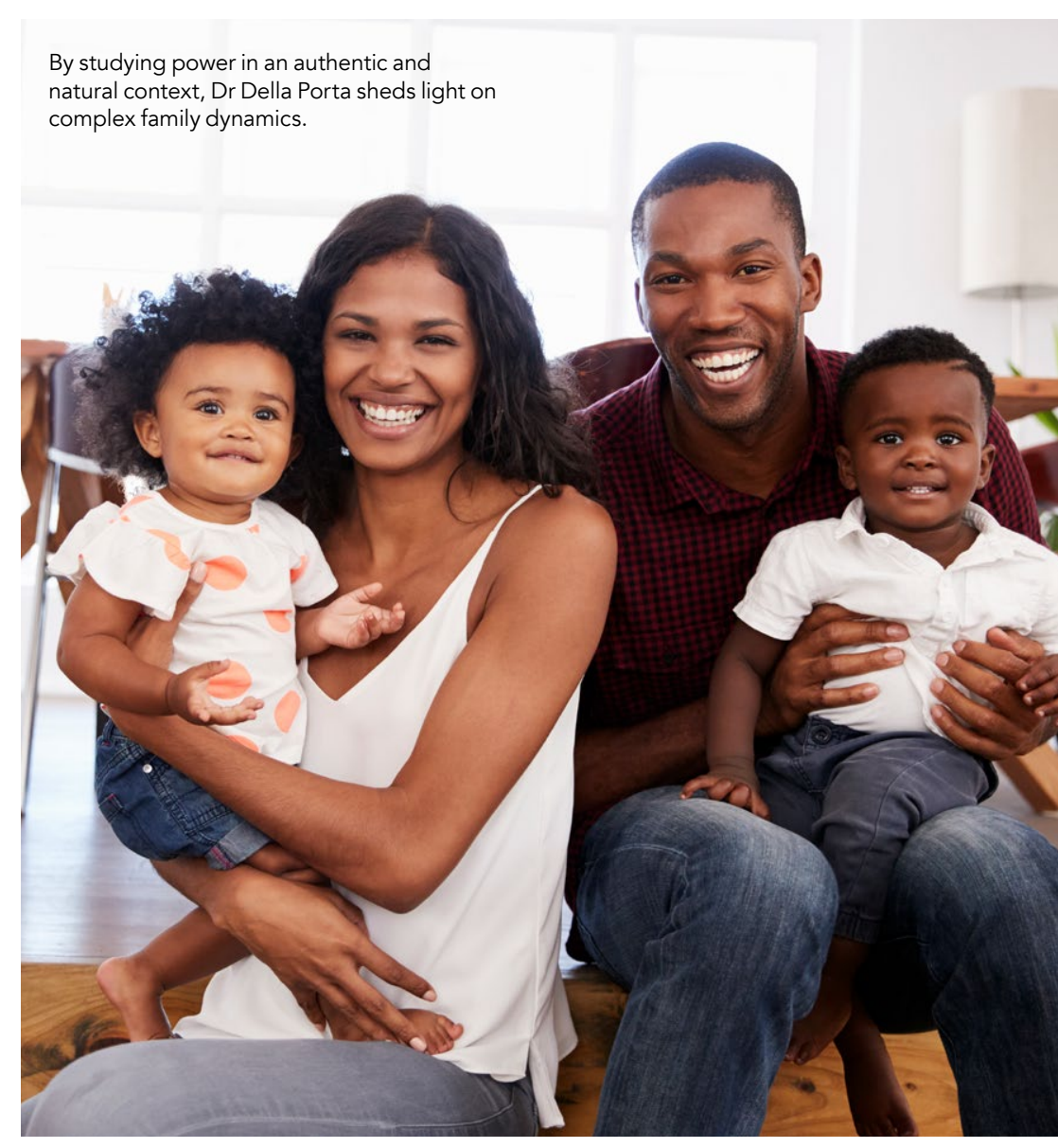

to be more prevalent within the first set of observations. Although, the findings did highlight that the effectiveness of 'simple' power was shown to increase over time.

Interestingly, the number of polyadic conflicts decreased over time, which is supporter by Dela Ponta's previous

\section{Studying family disagreements is an} important means by which researchers can investigate children's use of power strategies.

more complex. This represents the maturation in children's language skills once they are of school age. Dell Porta believes the more advanced power use by younger siblings could be due to their experience of complex interactions involving their parents and older siblings. However, the research 'sredictions were not completely met, as both time periods when it was expected involvement being needed less in conflict management or because conflict is more likely to involve just the parent and the child, rather than multiple parties. In addition, the research findings showed partial support for the influence of birth order upon the effectiveness of power strategies. Four-year-olds, who were the younger sibling, showed more successfully use of 'reward strategies, an older sibling. These younger siblings demonstrated a greater use of negative which wh hin their power strategies, which may have been employed specifically to gain support from parents. Della Porta has speculated that this may be effective because of parental trends towards perceive younger siblings as the

Della Porta's research provides important insight into how children's con be impacted by bith order. The use of family conflict frames these findings within an authentic and natural context involving complex family dynamics. This study, along with Della Porta's previous of social-cognitive development in early childhood, highlighting how children learn to navigate the socia world around them. Della Porta suggests that further research in this pea should look to assess how these power strategies are transmitted across other social relationships, as well as unther assessing how these power beliefs and behaviours. research, illuminates the process

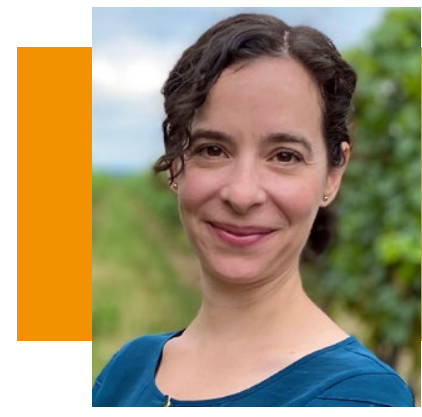

Behind the Research Dr Sandra Della Porta

E: sdellaporta@brocku.ca T: +19056885550 x5558 W: www.sandradellaporta.com

\section{Research Objectives}

Dr Sandra Della Porta researches social power within early childhood, particularly within a family context.

\section{Detail}

\section{Address}

1812 Sir Isaac Brock Way, St Catharines,

Bio

Dr Della Porta has a multidisciplinary background in psychology and education, specialising in erly childhood In combination with her practical experience working with children, she has built a research programme studying social power and power dynamics as it exists in informal and formal learning contexts (eg, family exchanges, teacherchild interactions, social play).

Dr Della Porta is affiliated with the Bachelor of Early Childhood Education programme in the Department of Educational Studies at Brock University. brocku.ca education/programs/early-childhood-education

\section{Funding}

Social Sciences and Humanities Research Council of Canada; Concordia University Research Chair in Early

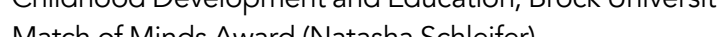

\section{Collaborators}

Ryan JPersan (Queen's University) Nina Howe (Concordia University), Hildy Ross (University of Waterloo)

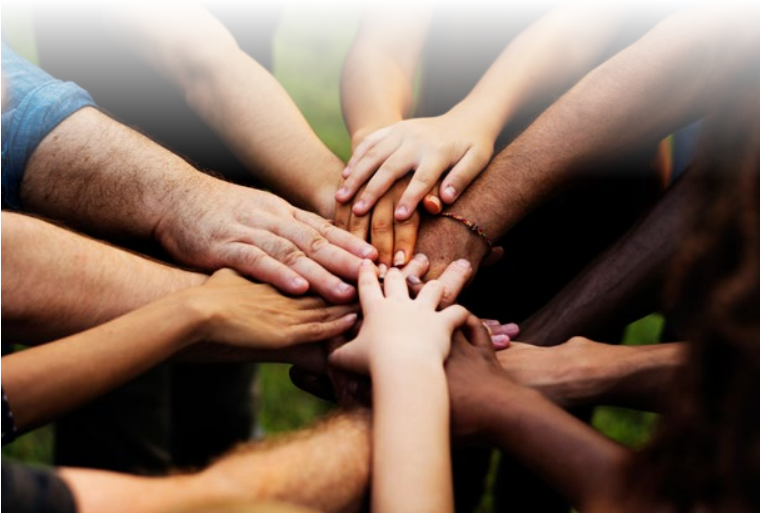

\section{References}

Della Porta, S, Persram, RJ, Howe, N, Ross, HS, (2021) Young children's differential use of power during family conflict: A longitudinal study. Social Development, 1-15.

Della Porta S, Howe N, Persram RJ, (2019) Parents' and children's power effectiveness during polyadic family conflic Process and outcome. Social Development, 28, 152-167.

Della Porta, S, Howe, N, (2017) Siblings' power and influence in polyadic family conflict during early childhood. In N Campione-Bar (ed), Power, control, and influence in sibling and Adolescent Development, 156, 15-31.

Della Porta, S, Howe N, (2012) Assessing Mothers' and Children's Perceptions of Power Through Personal, Conventional, and Prudential Conflict Situations. MerrillPalmer Quarterly, 58(4), 507-529.

\section{Personal Response}

\section{How do you hope clinicians will use your resear} findings to help support families with young childre

II Research findings from these four studies speak to the complexity of social power, as it begins to develop in young children within the family system. Social power varies by type of relationship, age, birth order, and conse these findings to recognize that social power can use these fintiss to recognize ha, and cal power does children's developing agency, assertiveness, and mediation skills. It is the exercise of constructive conflic resolution through power strategies that impacts family functioning and relationship interactions. Thus, it is not about who has the power but how power is used and fostered in a healthy manner. 